\title{
The Employment Equity Act (EEA) as an Instrument for Employment Equity in the South African Labor Market
}

\author{
Divane Nzima \\ Sociology Department, University of Fort Hare \\ Private Bag X1314, Alice, 5700, South Africa \\ Email:dnzima@gmail.com \\ Vusumzi Duma \\ University of Fort Hare \\ Email:vduma@ufh.ac.za
}

\section{Doi:10.5901/mjss.2014.v5n9p578}

\section{Abstract}

This paper seeks to critically examine the Employment Equity Act (EEA) as an instrument of achieving employment equity in post apartheid South Africa. Special emphasis will be placed on the policy of affirmative action. In this article we will attempt to illustrate how focusing on affirmative action and failure to implement policies could pose a threat to the achievement of equity in the South African labour industry. This paper was prepared by means of a literature survey wherein various previous literatures were interrogated including the actual Act in concern. In a nutshell it can be argued that the EEA as a piece of legislation has managed to augment equality in opportunities at the same time addressing the past imbalances. However there are concerns that affirmative action may pose a challenge as it is presented in discriminatory language and if handled carelessly may undermine merit, leading to disenfranchisement of deserving individuals. Another concern is that it could be used as a front by the political elite to harbor elements of corruption and nepotism to the disadvantage of the poor of the poorest amongst designated groups.

Keywords: Employment equity; Affirmative Action; Equality; Discrimination; Industrial Relations.

\section{Introduction}

South Africa is one of the countries that have experienced one of the most cruel and oppressive political system in the world in the form of apartheid. The release of Nelson Mandela in 1990 and the subsequent birth of a new democratic South Africa in 1994 have enabled the emergence of human rights standards and labour practices that advocate for the principles and the practice of equity and fairness. This culture of equity and fairness has been institutionalized through legislation such as the Employment Equity Act (Act 55 of 1998) which is aimed at addressing the imbalances of the past. During the era of apartheid, blacks, women and the disabled were systematically marginalized in the labour practices. Ellman, (1963) argued that, though evidence pointed to the growing importance of women in the world of business, a very limited number occupied significant positions compared to their male counterparts. Drawing from the above assertion, it is evident that the issue of gender fairness in employment has been a debated issue since the sixties. Previous studies indicated most of the influential positions in the work place were held by males, specifically white males. Marginalized groups such as blacks, women and the disabled occupied positions of less influence, lower status and lower pay (Humphries \& Grice, 1996; Jackson, 2001). Thus the purpose of the Employment Equity Act (EEA) has been to enable fair labour practices in ensuring that blacks, women and the disabled are accorded equal opportunities in the workplace. In this literature survey, we will critically examine the EEA as an instrument of achieving employment equity in post apartheid South Africa. Special emphasis will be placed on the policy of affirmative action. In this article we will attempt to illustrate how focusing on affirmative action and failure to implement policies could pose a threat to the achievement of equity in the South African labour industry.

\section{Contextualizing Apartheid Equality at the Workplace}

It is essential to have an understanding of some of the salient features of the apartheid regime in order to clearly 
understand problems of equity in the South African labour environment. The oppressive apartheid system through its regulations and some of its most unjust historical events negatively tainted many societal concepts, amongst others, the concepts of group classification, group rights, ethnicity, race, minority rights, and self-determination. Apartheid was deeply characterized by its central policy of 'divide and rule'. This unjust policy was aimed at ensuring white survival and hegemony. This was achieved through the division of the non-white population along racial and ethnic lines an act that was aimed at weakening this group (Kashula \& Anthonissen, 1995; Bennett, 1995).

Consequently, the corresponding majority was divided into a host of minority groups, which could no longer pose a threat to the white minority (including both the Afrikaners and the English population). Given the above arguments, one can argue that the apartheid system could also be safely described as a scheme to disempowering the non-white population while giving privileges to the white population, and especially the white Afrikaner population. Consequently, other scholars described the apartheid system as a pervasive system of affirmative action for the white population and especially for the Afrikaners (Sachs, 1992; Sonn, 1993). We therefore argue that the systematic marginalization and racial segregation of women and the non-white population before 1994 created a skewed playing field in the labour industry. As a result women and non-white populations failed to benefit from financially rewarding positions in the workplace as they were often pushed to the peripheries and reduced to manual labourers who could not occupy any positions of significance. With the emergence of democracy in 1994 stringent measures had to be taken in order to redress the misfortunes and imbalances of the past. Just like other established and emerging democracies South Africa was forced to enforce a level playing field in the work place to achieve equity, this prompted the introduction of new legislation consistent with universal human rights standards.

\section{South African Trends on Equality}

The New Constitution of South Africa guaranteed everyone the fundamental right to equality. The elimination of unfair discrimination and the adoption of positive measures to redress social imbalances were important components to this end, and thus the Employment Equity Act was a necessary step towards the achievement of the constitutional goals. The Employment Equity Act was incrementally promulgated into law in 1999. Human (1996) indicated that South African organizations were playing the numbers game. They did not realize that affirmative action is the process of creating equal employment opportunity and that it required fundamental changes to the human resource culture. Human (1996) argued that affirmative action and employment equity both encompassed, and were encompassed by, the concept of managing diversity. As a result there was an urgent need for the government to draft legislative interventions. Women marched to the Union Buildings in 1956 and they sang a song: "Wathint' Abafazi, Wathint' Imbokotho, Uzakufa!" When translated it means you have tampered with the women. You have struck a grinding stone. The then Minister of Labour said that the Employment Equity Act gave the women another grinding stone - another powerful tool. According to him the Act was a pledge to spare no effort in the struggle for gender equity (Mdladlana, 1999a). On 29 July 1999 Steve Tshwete (at a function to launch Affirmative Action Programme in the Police Force) made the following comment: "We do not only want to see leaders emerging from the male section. We want to see women being given positions in the command structures". He also said that South Africa has not yet arrived - where men and women were treated equally (Mdladlana, 1999b). Using the Breakwater Monitor results of 1998, Thomas, (2002) indicated a lower percentage of only $14 \%$ of managers were women.

Human (1996) indicated that in South Africa, which has a strong patriarchal attitude, male managers doubted the business abilities of women. These attitudes led to practices, which inherently put women at a disadvantage through deeply entrenched stereotyping of gender. According to a report released in 1999 by the Gender Commission, most companies preferred employing men to women because of a lack of gender policy, lack of trust in women, cultural views and resistance by male employees (Mdladlana, 1999a). The report also indicated a variance in income between men and women, for the same job. Thomas (2002) supported this viewpoint by indicating that male wages were $43 \%$ higher than those of similarly qualified females in the same sectors and jobs. The ideology of male superiority was a system of beliefs that set a male standard, which became the yardstick with which women were judged when they entered male-dominated posts.

So, the glass ceiling still remained. The term "glass ceiling" indicated those invisible barriers that kept women from rising above a certain level in organizations (Jackson, 2001). It seemed that gender discrimination was so deeply embedded in organizational life that it was part and parcel of the organizational culture (Cassell, 1996). Burke and Mattis (2000) noted that even when women do all the right things and had the right competencies; they were still blocked from the inner most circles of power and corporate board level. It seemed as though, internationally, the Equal Employment Opportunity legislation had not worked that well. Legislation had brought the discrimination to the fore, but could not curb 
systemic discrimination. In South Africa, the Employment Equity Act was seen as a tool to ensure the upward mobility of women, other designated groups and those who are physically challenged in the labour market and to break the glass ceiling that had prevented women from growing and having the same access to job opportunities as their male counterparts (Mdladlana, 1999a).

\section{Measures to Address Inequality in the Workplace}

\subsection{Legislative interventions}

Many countries around the world have adopted various legislative interventions in an attempt to address the question of inequality in the workplace. The most popular among the many interventions are the Equal Employment Opportunity (EEO) and Affirmative Action (AA) policies which have been introduced in various countries across the globe to address this issue about fairness and discrimination in the workplace. Despite these attempts, Hamphries \& Grice, (1995) argued that inequality continued to persist. Post 1994 South Africa also adopted the equal Employment Opportunities (EEO) and Affirmative Action (AA). This was a very important undertaking given that the South African labour environment had been severely polarized. While democracies such as South Africa sought to address the inequality debacle, Mavin, (2001) argued that male career models and approaches did not disappear from the scene, however they remained. In addition he argued that women were being disadvantaged when they stepped out to meet family responsibilities. In many societies women are regarded as the center of the family and usually expectations are very high for them to take charge of family responsibilities. This is one of the areas of debate where feminists have often attacked the patriarchal model of society. According to Marvin, (2001) women were subtly forced to choose between upward mobility in career and family stability in the home, or later alone starting a family. South Africa as an emerging economy has therefore shown its commitment to addressing inequality by adopting supportive legislation to abolish this very pertinent issue in the labour environment.

The Employment Equity Act (EEA) No. 55 of 1998 of the Parliament of the Republic of South in Section 2 describes its purpose as follows.

To achieve equity in the workplace by:

a. Promoting equal opportunity and fair treatment in employment through the elimination of unfair discrimination; and

b. Implementing affirmative action measures to redress the disadvantages in employment experienced by designated groups, in order to ensure their equitable representation in all occupational categories and levels in the workforce.

According to Thomas, (2002) International and national Employment Equity Legislation, is aimed at ensuring the equitable representation of women and other designated groups in all occupational categories and levels in the workplace. Within these legislations and related literature various concepts of Employment Equity are used constantly. It is our opinion that perhaps it would be useful to investigate what equal employment opportunity encompassed. According to Toumishey, (2001), Employment Equity is often seen as a long-term programme to ensure that all employees have a fair chance in the workplace. The EEA prohibits direct and indirect discrimination on a number of grounds, including:

- Race, ethic or social group, colour and culture

- Gender, sex, pregnancy and sexual orientation

- Disabilities and HIV status

- Religion, conscience, belief and language ( Section 6 of EEA)

Other scholars have acknowledged that amid challenges of inequality evident in the male dominated workplace and a society that has internalized a culture of segregation and discrimination owing to dark forces of the past, Employment Equity will only be achieved when no person is denied employment opportunities or benefits for reasons that are not related to their abilities (Thomas, 2002, Toumishey, 2001).

\subsection{Affirmative Action.}

In the South African context, Affirmative Action is an important instrument through which Employment Equity is hoped to be achieved. Some scholars have argued that Affirmative action is seen as a short-term strategy by which equality (employment equity) in the workplace would be achieved as it is anticipated that this will help in the active elimination of systemic discrimination (Thomas, 2002, Toumishey, 2001). Systemic Discrimination, one could argue, occurs when 
groups of people, for instance women, are excluded from the workplace for reasons not related to inherent requirements of the job. In many cases this unfortunate phenomenon results from entrenched policies and practices that are part of the normal operation of employment systems that unintentionally discriminate (Toumishey, 2001). Human, (1996) saw Affirmative Action as the process whereby equal employment rights were created, cutting across all Human Resource (HR) practices such as selection, recruitment, induction, development, and many others. The above statement is supported by Chapter 3 of the EEA that advocates for the 'designated groups' as we have seen are black people, women and people with disabilities. This referred to a more holistic focus such as diversity management. According to McWhirther, (1996) the most legitimate justification for engaging in affirmative action is the need to compensate for specific past instances of race and gender discrimination by particular organizations. There is need to remedy 'societal discrimination' because some organizations may have engaged in intentional discrimination in the past and so have other entities in society. The justification for affirmative action is the need to create more diversity in particular organizations. McWhirther, (1996) argues that Affirmative action programmes have certainly increased the labour force participation rate for women and blacks.

However it could be argued that though affirmative action is a redress policy for the sins of the past, it still uses discriminatory language. Perhaps emphasis must be placed on that it is a temporary measure to level the playing field until such a time when proper policies devoid of any discriminatory language of any sort could be adopted. At present much as Affirmative action serves a worthy purpose it poses a threat of excluding deserving and valuable talent in preference of meeting the quota of designated groups.

According to Thomas, (1997) diversity management is a planned, systematic and comprehensive managerial process for developing an organizational environment in which all employees, with their similarities and differences, could contribute to the strategic and competitive advantage of the organization, and where no one was excluded on the basis of factors unrelated to productivity. The main issue in equality is ensuring fair treatment for all. As long as one has the qualification and experience for the job they should be rewarded on merit. As we have alluded before, there is a need to guard against compromising quality in the name of affirmative action and there should be great effort put to ensure that people are not discriminated based on factors that have nothing to do with the inherent requirements of the job. Both Affirmative Action and diversity management should lead to equal employment opportunities, which was the ultimate goal. It remains important to remember that to avoid creating reverse polarization affirmative action should only be treated as a stepping stone towards a level playing field.

Zelnick, (1996) regards affirmative action as a racially discriminatory practice against whites and other favored ethnic groups. It favors the less qualified over the more qualified and therefore a systematic attack upon objective merit selective criteria. According to Zelnick, (1996) while affirmative action has exhibited positive strides in that it increases black enrollment at selective universities, companies and also expands somewhat the pool of black entrepreneurs it has brought little employment, educational or income benefits to those in most need of help. Perhaps to add on this flip side, in certain instances the policy is exposed to elements of corruption, nepotism and the advancement of the interests of the political elite. However the EAA section 15 states that affirmative action measures are intended to ensure that suitably qualified employees from designated groups that have equal employment opportunity are equitably represented in all occupational categories and levels of the workforce. Much as this is the written law, the South African labour environment is also prone to illicit cultures such as deployment of cadres by the political elite. This severely disenfranchises well deserving individuals of all races and genders. Zelnick, (1996) further argues that affirmative action has been broadened for political purposes to include beneficiaries who lack the historical claim of blacks for relief.

While the EEA and the policy of affirmative action are well intended and seek to address a worthy cause, the poor implementation suggests that these are based on political empowerment and not on economic empowerment. Contrary to the view of the ANC Department of Economic Policy (1990), affirmative action does not exhibit a temporary nature. It does not appear as a transitional method of bridging the equality gap as was once claimed by the ANC Department of Economic Policy. In March 2007, the then Minister of Labour, perhaps the most fervent advocate of Employment Equity (EE) and Affirmative Action (AA) stated that AA will never be removed from the statute books. One can argue that the EEA discriminates one group and prefers another group. It could also be argued that this piece of legislation is an employment discrimination law, albeit a legal discrimination. It adopts the doctrine that the end justifies the means. It argues that if the intentions are noble then the means to attain those ends must also be noble. It fails to accommodate the least privileged of blacks and women as they often lack political connections. It tends to increase the economic status among blacks and women of those already relatively advanced in comparison to the poorest of the poor. Though Affirmative action is well intended given the injustices of the past and the need to level the playing field, as long as there is persistent poor implementation and failure to define the cut-off date for this policy, there is no justification that all forms of affirmative action do not violate the principles of equal opportunity before the law and thus do not contravene the rule 
of law.

\section{Conclusion}

In this article we have examined the Employment Equity Act (EEA) No. 55 of 1998 as an instrument to bring employment equity in South Africa. Special emphasis was given to the policy of Affirmative Action (AA). As much as The South African government has sought to redress the historical legacy of workplace discrimination by introducing the Employment Equity Act (1998), there are still grey areas that need to be addressed especially with regards to the implementation of this piece of legislation. It is evident that the EEA is well intended and has made great strides in enforcing workplace equality in that it has ensured that the blacks, women and all the previously disadvantaged have been accorded a somewhat equal legal claim to the opportunities in the employment sector. This in itself has entailed good strides at enlarging the sphere of fairness, although there are still some concerns over whether the issue of employment equity is really practiced as well as the fairness of affirmative action. In a nutshell it can be argued that the EEA as a piece of legislation has managed to augment equality in opportunities at the same time addressing the past imbalances. However, there are concerns that affirmative action may pose a challenge as it is presented in discriminatory language and if handled carelessly may undermine merit, leading to disenfranchisement of deserving individuals. Another concern is that it could be used as a front by the political elite to harbor elements of corruption and nepotism to the disadvantage of the poor of the poorest amongst designated groups.

\section{References}

Burke, J.R. \& Mattis, M.C. (Ed). (2000). Women on Corporate Boards of Directors. International Challenges and Opportunities. Dordrecht: Kluwer Academic Publishers.

Ellman, S.E. (1963). Managing Women in Business. Connecticut: Prentice-Hall

Employment Equity Act no. 55 of 1998, of the Parliament of the Republic of South Africa.

Human, L. (1996). Managing Workforce Diversity: a critique and example from South Africa. International Journal of Manpower, 17 (4/5), 46-64.

Jackson, J.C. (2001). Women middle Managers' perception of the Glass Ceiling. Women in Management Review, 16 (1), 30-41.

Humphries, M. \& Grice, S. (1996). Equal Employment Opportunity and the Management of Diversity. Journal of Organizational Change Management, 8 (5), 17-32.

Marvin, S. (2001). Women's Career in Theory and Practice: time for Change? Women in Management Review, 16 (4), 183-192.

Mdladlana, M. (1999a). Address: Launch of the Commission For EE and Chapter 2 of the Employment Equity Act.

Mdladlana, M. (1999b). Speech: Media launch of the Chapter 3 of the Employment Equity Act.

Thomas, A. (1997). Beyond Affirmative Action. Randburg: Knowledge Resources.

Thomas, A. (2002). Employment Equity in South Africa: lessons from the global world. International Journal of Manpower, 23 (3), 237255.

Toumishey, S.J. (2001). Most Frequently Asked Employment Equity Questions

Zelnick, B. (1996). Backfire. Washington D.C: Regnery Publishing 